\title{
Development of school energy policy and energy education plans: A comparative case study in three Wisconsin school communities
}

\author{
Jennie F. Lane ${ }^{\mathrm{a}, *}$, Kristin Floress ${ }^{\mathrm{b}}$, Melissa Rickert ${ }^{\mathrm{c}}$ \\ a Graduate School of Education, Bilkent University, Ankara 06800, Turkey \\ b College of Natural Resources, University of Wisconsin, Stevens Point, Stevens Point, WI, USA \\ ${ }^{\mathrm{c}}$ Certified Energy Manager, CESA 10, Chippewa Falls, WI, USA
}

\section{H I G H L I G H T S}

- School energy policy and complementary energy education plans can be successfully developed with guidelines for policy team membership.

- Teacher agency, including environmental literacy, helps overcome barriers in developing school policy and energy education plans.

- Administrative support of energy conservation is a key to the development of school energy policies and complementary energy education plans.

\section{A R T I C L E I N F O}

\section{Article history:}

Received 10 July 2013

Received in revised form

22 September 2013

Accepted 1 October 2013

Available online 30 October 2013

Keywords:

School buildings

Energy education

Policy development

\begin{abstract}
A B S T R A C T
Through a qualitative comparative case study, this investigation examined the process by which three school districts in Wisconsin, U.S.A., developed a school energy policy and complementary energy education plan. To guide the process, the researchers created an outline of recommended steps for the districts to follow. Although there were variations in the sequence and perceived ease of the steps, the Energy Task Force members involved in the process found the outline to be a supportive guide. Further analysis of the cases involved interviewing members of the Energy Task Forces to identify facilitating and obstructing factors. The study concluded that factors such as level of environmental literacy, along with aspects of the school culture and leadership, interacted to influence the successful drafting of school energy policies and education plans. In addition to introducing an outline of recommended steps that can be used by other school policy development teams interested in promoting energy efficiency, this study adds insights into the analysis of energy policy work within the context of a school setting.
\end{abstract}

๑) 2013 Elsevier Ltd. All rights reserved.

\section{Introduction}

America's primary and secondary schools spend more than \$6 billion annually on energy (Orth, 2009). With rising energy costs, school districts must find ways to effectively manage their energy consumption. One strategy is to develop a school policy to promote energy efficiency; another is to increase awareness of energy consumption through energy education. Ideally, administrators, energy resource managers, and teachers can be involved in both strategies in conjunction (Rickert, 2011). The Wisconsin K-12 Energy Education Program (KEEP), a statewide energy education program in Wisconsin, was interested in promoting the development of energy policy and education plans in the state's schools. To address this interest, KEEP created the school energy policy and education plan (SEP\&EP) grant program and developed an outline for schools to utilize during their SEP\&EP development. Three

\footnotetext{
*Corresponding author. Tel.: +905388 610816 .

E-mail addresses: jennie.lane@bilkent.edu.tr, farberlane@gmail.com (J.F. Lane).
}

school districts were awarded grants. KEEP sponsored a comparative case research study of the three districts - in particular their Energy Task Force members - to gain a better understanding of how the outlined steps were used. A primary focus of the study was to identify factors which the Energy Task Force members perceived facilitated or obstructed the school energy policy and education plan development, with the desired outcome of improving the process for other schools intending to do similar work. Although this study focused on specific cases in one state of the United States, there were lessons learned and research opportunities discovered for school energy policies and education plans in schools worldwide.

\section{Energy education in schools}

There are many approaches to energy education. These include classroom lessons, school-wide motivational presentations, teacher in-services, and school energy fairs. One approach in particular using the school building as a learning resource - is especially 
germane to promoting school building energy efficiency. This approach aims to involve teachers and students in analyzing their school building's energy consumption. For example, in the United States, the National Energy Education Development Project (NEED) provides free energy education resources to K-12 teachers to help their students apply energy concepts while examining energy systems within the school (NEED, 2012). Another example in the United States is Alliance to Save Energy's Green Schools Program. This program works on a district level to create a customized plan for teaching about energy, saving energy in school, creating schoolwide energy awareness, and taking the message home and into the local community. A team of teachers, custodial staff, administrators, and students carries out the program at each school. A Green School improves education through hands-on, real-world learning about energy and energy efficiency and strengthens schools by saving money on energy costs (Alliance to Save Energy, 2009). The recommendations for saving energy that result from these programs and others range from low cost initiatives, such as promoting lights-off campaigns for vacant classrooms, to more expensive endeavors such as upgrading boilers and furnaces. To further support the implementation of these recommendations, some schools develop energy policies.

\section{School energy policy}

Development of school energy policy is recommended by the U.S. Department of Energy's EnergySmart Schools Program (U.S. Department of Energy, 2009). A few of the Department of Energy's major conclusions include (1) high energy costs are not "fixed" and can be reduced five to twenty percent by effectively managing, maintaining, and operating school physical plants, regardless of school age, (2) distribution of school-specific information to building staff is essential, and (3) detailed energy policy should provide guidelines for operation and maintenance programs (Princeton Energy Resources International et al., 2004). A policy communicates consensual protocol and practices, and aids in decision making and goal setting. According to the U.S. Environmental Protection Agency (EPA, 2005), organizations that establish energy management policies and procedures outperform ones without such policies. Bontrager and Hubbard (1977) emphasized the importance of a school energy policy, largely in response to the energy crisis. By having practical, enforceable energy policies in place, school districts will likely realize a reduction in their energy consumption that translates into lower utility bills - which is increasingly important in today's economic climate.

In the field of education, school policy is usually established by the respective school board in order to convey goals and procedures about a myriad of topics, ranging from school lunches to curriculum development to bullying. Various aspects of the effectiveness and implications of policy have been researched, including how policy is influenced (Gittell, 1995), the importance of embedded research to policy (Allington, 1999; Superfine et al., 2010), and outcomes of interactions among policies (Chrispeels, 1997). For many years, researchers have been advocating effective policy development practices for schools. Stanley (1957) promoted employing teachers and community members in school policy development as a means of increased participation, and Stevenson (2006) urged engaging educators in policy discourse. Stevenson (2007) discussed relationships between policies and environmental rhetoric and practice, and recommends improving discourse in professional communities to enact meaningful environmental education in schools. Other studies have investigated the significance of teacher attitudes and involvement in school policy-making (Cavallo et al., 1998; Witcher, 2001). Braun et al. (2010) conducted a long-term qualitative study of school policy enactment and implementation. The study introduces their policy enactment theory, which provides valuable insights into policy development. This theory stresses that "policy enactment involves creative processes of interpretation and recontextualisation - that is, the translation through reading, writing and talking of text into action and the abstractions of policy ideas into contextualized practices" (p. 549). In a related study, Ball et al. (2011) sought to further analyze the role of policy actors in policy work, identifying the positions of those involved, and labeling them with titles such as narrators, enthusiasts, and critics. Through interpretation and translation, the actors involved in policy work seek to understand the process in ways complementary to their roles and responsibilities.

The current study extends the analysis of policy work by means of an exploratory examination of teams focused on developing school energy policy and education plans. A constructive analysis of the policy actors' perspectives of factors that obstruct or support policy development builds an awareness of the complex nature of policy work. It is hoped that this analysis will facilitate the creation of teams that can work productively to develop school energy policies and education plans to help schools save energy and money.

\section{Project background}

The Wisconsin K-12 Energy Education Program (KEEP) was created by the Wisconsin Center for Environmental Education (WCEE) in 1995 to improve and increase energy education in Wisconsin. The WCEE developed KEEP largely in response to the results of a statewide environmental literacy assessment it conducted in 1992. The assessment revealed that students lacked an understanding of many important energy concepts (Champeau, 1997). The assessment was based on an environmental literacy framework developed by the WCEE after a comprehensive review of environmental literacy research (Peri, 1996). The assessment framework included four outcomes: Cognitive Learning Outcomes, Affective Learning Outcomes, Environmentally Responsible Behaviors, and Efficacy Beliefs. DeWaters and Powers (2011) used a similar framework to assess the energy literacy of students in New York in 2008.

As with many energy education programs, KEEP provides professional development and support materials for schoolbased energy education initiatives. In addition to offering courses, activity guides, and resources for teachers, KEEP was interested in helping schools create energy education planning that would enhance the development of school energy policies.

To help determine if schools in Wisconsin were interested in developing or updating their energy policies, the Wisconsin Green Building Alliance Green Schools Committee sent a Green Schools Survey to school district business officials in Wisconsin. Survey results indicated that 47 percent of responding districts had enacted an energy policy. When asked if their district would be interested in updating or creating an effective energy management policy, 79 percent responded affirmatively (Panaro and Rickert, 2011).

The results of the Green Schools Survey motivated KEEP staff to create a school energy policy and education plan (SEP\&EP) grant program. The goal of the program was to help school districts (either one building or district-wide) form an Energy Task Force that would develop or update the school policy and create a plan to integrate energy concepts into the school or district curriculum. Through this program, schools would garner useful insights into the policy and plan development process; they would also explore the potential financial benefits of developing, adopting, and implementing wise energy policies that reduce energy consumption, minimize energy waste, and increase energy efficiency in all areas of the school. The Request for Proposals for the grants included an outline of steps for creating a school energy policy and education plan (see Appendix). 
Applicants submitted proposals explaining how the steps would be applied to their setting. Essentially, the steps involved (1) forming an Energy Task Force comprising selected representatives from a school facility (administrators, facility managers, and teachers), (2) arranging for the Energy Task Force to participate in an energy audit of the school, (3) following a template to develop a draft of the SEP\&EP, (4) soliciting feedback from school personnel and community members regarding the draft, (5) providing progress reports to the community, (6) ensuring professional development for the teachers, (7) enrolling administrators and facility managers in school building energy use and efficiency trainings or workshops, and (8) revising the document and presenting it to their administering body. Grant funds were primarily used for compensating Energy Task Force members for their planning time. During the first year of the SEP\&EP grant program, eight Wisconsin school communities applied for funding and three were granted. The comparative case study research was conducted to help KEEP gain insights into how the outlined steps were used in the three districts, and to aid the improvement of the process.

\section{Methods}

To achieve the desired depth of understanding of the SEP\&EP development process, a qualitative comparative case study method was used. The cases included the members of the Energy Task Forces from three school districts involved in the process. While the findings may not be generalized across all schools, they may be transferable to other teams interested in developing an energy policy and associated energy education plans.

\subsection{Case selection}

Cases for this study were selected through a grant application process. The application mirrored the steps outlined for completing a school energy policy and education plan. The Request for Proposals for the grant was announced statewide (to Wisconsin's 424 school districts) through various education outreach networks. Eight applications were received. Possible reasons for this small response included that this was the first time the grant was offered and the perception that energy policy work is challenging and often a novel prospect for school districts. A grant review panel composed of energy resource managers, KEEP staff, and a stakeholder representative from the funding agency reviewed the applications. School Districts A, B, and C were awarded grant funding based on the quality of their applications, particularly the ways in which they addressed the criteria outlined in the Request for Proposals. The membership of the Energy Task Forces included school and community representatives as recommended in the outlined steps.

School District A, located in northeast Wisconsin, had approximately 750 students and 55 staff members. There were three primary Energy Task Force members involved in developing the SEP\&EP. At the time they began working on the plan, two of the Energy Task Force members were teachers in the high school and one was a member of the administration team for the district. There was no representation from the middle or elementary schools in the development process. At times, other individuals participated in the Task Force including the district's new Superintendent and a member of the school board who had an interest in energy management. The district did not have any formal energy policies in place before this project began. The Energy Task Force developed most of the energy policy and education plan during the summer of 2009. There were two school buildings located on the same property in District A.

School District B, also located in northeast Wisconsin, had approximately 5700 students and 680 staff members. There were three primary Energy Task Force members involved in developing the SEP\&EP, including one elementary, one junior high, and one high school teacher. This group focused on developing an education plan because an energy policy already existed for the district. The district approved a school energy policy between the time the grant was submitted and the time it began working on the SEP\&EP. The district strongly supported the development of the energy education plan because of the recent adoption of the energy policy. To ensure compliance with the policy, the Energy Task Force often involved other district and community members who were familiar with the policy. The Energy Task Force met once a month for 17 months from August 2009 to December 2010, primarily working on the energy education plan. There were eight school buildings in District B, located throughout the community.

School District C, located in south central Wisconsin, had approximately 6000 students and 850 staff members. There were eight primary Energy Task Force members involved in developing the SEP\&EP, including the District Business Official, District Energy Manager, an energy education consultant, three elementary teachers, and two high school teachers. The district approved energy policies in 1986, but was interested in updating them. There was support from the administration to develop the SEP\&EP. The Energy Task Force met occasionally from May to November 2010. There were 10 school buildings in District C, located throughout the community.

\subsection{Data collection}

The comparative case study began in July 2009 with observations of District A's first SEP\&EP development meeting and concluded in January 2011 with the submission of District B's final SEP\&EP. Between ten and fifteen SEP\&EP development meetings were held in each district. SEP\&EP development meetings included reviewing existing school energy policies and/or energy curriculum, touring a school facility on an energy audit, drafting policies and/or curriculum, and attending school board meetings and teacher in-services.

The main source of data for the analysis of the facilitating and obstructing factors perceived by the Energy Task Forces was transcripts from a final interview conducted by a graduate student employed by KEEP. Each interview question was directly related to a research question for the study. The interview items were reviewed by a panel of experts prior to use to ensure face validity. There were 14 participants involved in the final interviews comprising three Energy Task Force members from District A, three from District B, and eight from District $C$. The individuals chosen for the interviews were selected because they were primary members of their respective Energy Task Forces. Of the eight interview questions asked, items related to perceived factors that facilitate or obstruct the SEP\&EP development process included the following:

1. What experiences do you bring to the SEP\&EP development process?

2. What facilitators aided in the development process?

3. What, if any, are your concerns regarding this development process?

4. What barriers affected the SEP\&EP development process?

\subsection{Trustworthiness and limitations}

Given the small applicant pool and the subsequent selection of only three grant recipients, the study participants were not representative of schools throughout the state. However, the schools' locations, enrollments and grade levels were taken into consideration during the grant review process, enabling an investigation into varied school settings. 
The grantees were requested to participate in a research study to help investigate the development process for the SEP\&EP; it was made clear that participation in the study was voluntary and not a requirement of the grant. All three of the school districts which were awarded grants agreed to be a part of the comparative case study. The participants signed a consent form which explained the purpose, process, and confidentiality of the study.

The researchers, including the graduate student conducting the interviews, represented KEEP when they visited the schools during the SEP\&EP meetings. As the funding was provided through KEEP, there was a chance participants might be biased in their responses. However, the frequency of the visits and the ongoing communication helped develop a relationship with the Task Force members that encouraged candid exchanges and sharing of information related to the process. The participants were also assured their names and the school names would be kept confidential.

To strengthen the trustworthiness of the data, multiple sources of evidence were utilized to gain more in-depth information about the research project's research questions. Data collected prior to the interviews included observation notes, a review of supplementary documents, and a questionnaire. The researchers obtained data by observing the development process (i.e., attending SEP\&EP development meetings) and reviewing secondary documents such as minutes from school board meetings and energy audit reports. The questionnaire was given to Energy Task Force members to gather their perceptions of how involved they were in each step and the extent to which they found the steps easy or difficult to accomplish. The information from these sources was used to confirm and add credibility to the comments made during the interviews.

Once all of the data were collected, they were brought together and organized in a fashion that would allow easy access for the researchers during the analysis process (Merriam, 1998). Digital folders were developed comprising various electronic copies of documents. A spreadsheet with the relevant sources of data listed in chronological order was created for each school district. These strategies helped to provide the researchers with a "bird's eye" view of the data in total, facilitating access to make comparisons and find relationships. To compare the actual development process to the recommended steps outlined in the grant, the researchers created a flowchart and a timeline of events to illustrate the progress of each of the three districts. As themes were being formed, these additional sources of data contributed further insights into the groupings and categorizations. For example, an Energy Task Force member's interview responses about team interactions would be related to observation notes from meetings to help the researchers better understand the interactions.

\subsection{Analysis}

The overall data analysis was based on the general strategy of developing a case description. Explanation building, response matrix, coding and categorization (forming themes and subthemes), comparative analysis, and identifying representative quotations were all techniques utilized to develop a case description.

For explanation building, the analysis was a form of patternmatching, involving an iterative process to build a descriptive framework which organizes the case study (Yin, 2009). The response matrix and coding facilitated this process. For this study, the researchers started out trying to build an explanation for the first interview question using response summaries from the various data collection tools from District $A$. An initial explanation was formed; then data from District $B$ were analyzed and the explanation was revised based on the added evidence. Finally, data from District $C$ were added and the explanation was revised once again based on the data from all three districts. To confirm or disconfirm the explanations, data from the digital folders (observations, field notes, and documentation) were referred to during the analysis. In this way, the explanations became richer and more substantive as additional evidence was incorporated into the descriptions.

The response matrix was created after transcribing the interview responses. It was used to identify categories and common themes among responses. The responses from participants from each school district were paraphrased to reduce the volume of data required to conduct analysis. With the data in this format, the researchers could more easily begin the coding process of identifying five to ten response categories for each research question.

Coding involved the researchers reading the responses at least three times: when transcribing the interviews, when creating the response matrix, and when the categorization began. For each question analyzed, patterns in participant responses were identified and categories were developed using all three school district participant responses. The categories were arranged in order of most common responses to least common responses. The number of respondents was tabulated as well as which school district each respondent came from. Categories from the initial coding process were combined to form themes. One member of the research team took the lead on the categorization. To help ensure reliability, the other researchers independently reviewed and grouped samples of responses to determine if similar categories would be formed. The different researchers did create comparable groupings, which helped confirm the categorization and theme identification process.

The initial process resulted in 260 codes, which were grouped into 25 subthemes and organized within three themes: Experiences, Facilitators, and Concerns/Barriers. To better understand the emphasis of each subtheme, the number of respondents' comments that could be attributed to each subtheme was noted. Supplementary data from observation notes, questionnaires, and document reviews within the digital folders and spreadsheet were cross-referenced to illustrate the subthemes and provide further insight into their emphasis.

The themes and subthemes were then comparatively analyzed to explore the relationships among the facilitating and obstructing factors and to identify overarching phenomena. The relationships of the factors within the overarching phenomena helped develop a coherent description (explanation) of the SEP\&EP development process. Finally, relevant quotes of the transcribed interviews were used to illustrate the themes; these quotations helped represent the data that was collected and analyzed.

\section{Results}

The three school districts successfully completed their SEP\&EPs within the timeframe of their planning grant. Responses to the questionnaire revealed variations in the makeup of Energy Task Force membership and the order in which each district completed the outlined steps. Energy Task Force members found different steps more or less difficult based on their level of involvement. To provide deeper insight into the barriers and facilitators encountered, the researchers analyzed the perceptions of the Energy Task Force members regarding the overall process. These perceptions came primarily from the interview results, related with the supplementary data described above.

The comparative analysis revealed overarching phenomena that helped to explain relationships among the various factors that the Energy Task Force members perceived obstructed and facilitated the SEP\&EP development process. The two main phenomena were Institutional and Management Framework and Leadership and Team. Deeper analysis of the Leadership and Team phenomenon revealed attributes of environmental literacy: cognitive domain, 


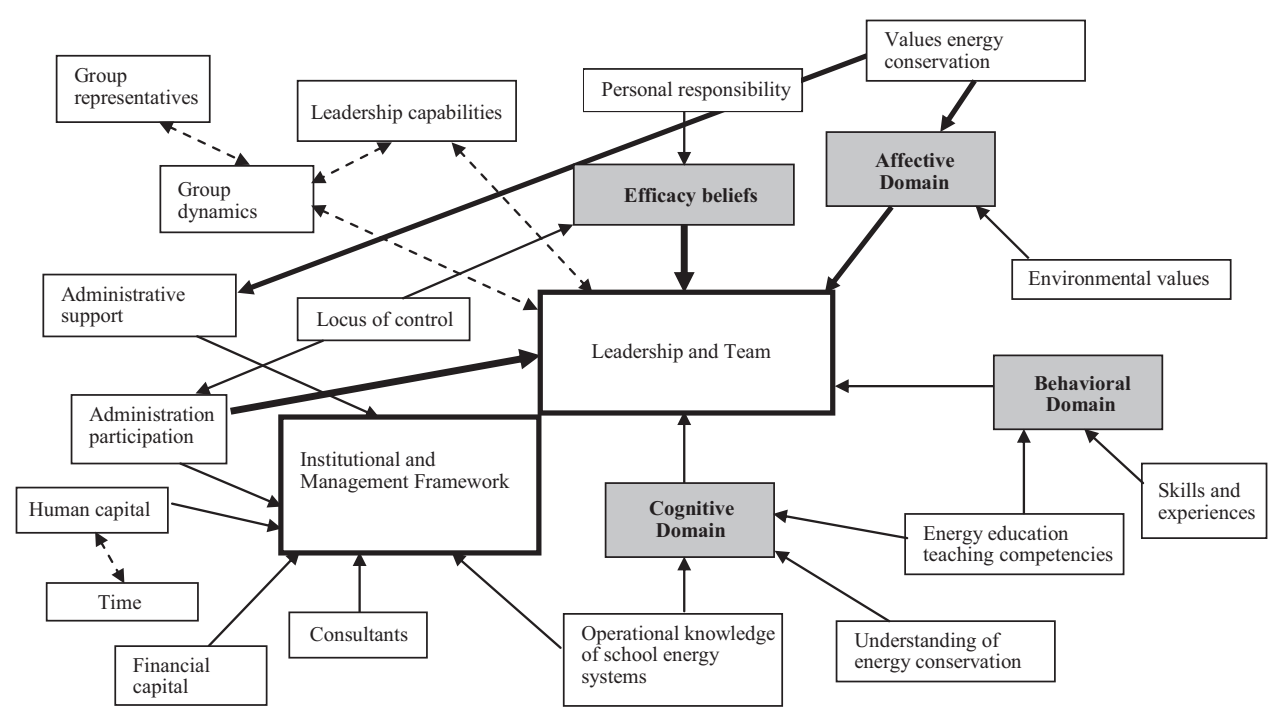

Fig. 1. Diagram of relationships among factors affecting energy policy and energy education plan development process.

affective domain, behavioral domain, and efficacy beliefs. Furthermore, it became apparent that these attributes helped those involved in the process overcome the obstructions and take advantage of other facilitating factors. Fig. 1 provides a diagram of the overarching phenomena and illustrates relationships among key factors that affect the SEP\&EP development process, including the environmental literacy attributes represented by shaded boxes. The graphic emphasizes facilitating factors: heavier lines represent factors perceived to be most influential and dashed double-pointed arrows indicate factors that could be barriers as well (e.g., group dynamics and time).

\subsection{Institutional and management framework}

Institutional and management factors include administrative support, financial capital, and time. Administrative support, especially from the school board, was one of the strongest facilitating factors for this study. The support the Energy Task Force members received from their administration, energy consultants, and energy professionals was similar among all three districts. Part of the grant application required the administrator's signature and a list of Energy Task Force members committed to developing the SEP\&EP.

One participant from District A provided the following comment when asked what facilitated the plan development process: "The willingness [of the school board] to approve a policy to take money out of the general fund and put it into a fund to pay for an internal grant process." In District B, the school board had recently adopted a school energy policy and they were looking to develop the education component of the policy. The Assistant Superintendent for Business Services for District $C$ played an integral role in the SEP\&EP development process for this district. He displayed passion and enthusiasm that helped lead the group through the process despite challenges to the group dynamics - note Values energy conservation in Fig. 1 . District $C$ also had an extremely supportive staff of administrative assistants and custodians who were happy to answer questions and provide documents as needed. Indeed, the involvement of someone in an administrative position of leadership increased both the likelihood that decisions would be implemented and the perception of others that their work will lead to change. If an administrator could not participate directly, knowledge that the administration was committed to implementing the SEP\&EP also helped facilitate the process.

Financial capital for this study means that individuals were compensated for the time they devoted to the process. When given compensation, participants are more likely to feel that they could spend the time on SEP\&EP development instead of other tasks vying for their attention.

Finally, as with many efforts in education, Time was an issue. Concerns ranged from having too short of a timeframe to get the plan completed, to meetings being too few and too far apart to sustain momentum. A common concern for District B was finding a time for the Energy Task Force to meet consistently. A few members could attend the majority of the meetings, but many missed several because they were involved with other activities. One participant from this district suggested "[a schedule that ensures] larger chunks of time where we can just get into it, get at it, keep going, and get done versus starting and stopping and having to figure out where you are." The fact that there was compensation for their time through the grant encouraged participation of those who otherwise may not have been involved.

\subsection{Leadership and team}

Leadership characteristics were important to the SEP\&EP development process. The leadership components that constrained or facilitated development included a strong Energy Task Force leader who was dedicated to keeping the team moving forward, as well as leadership from the administrative level to help guide the way throughout the process.

In District A, the Energy Task Force was composed of a diversity of knowledgeable key players including a school board member, custodian, superintendent, Energy Advisor, and teachers. One District A participant stated, "I think we worked really well together. We always found time to come in together. We did our fair share outside of the time we were together. I think we didn't have any weak links. I just think we were a very good team." Positive interactions among group members can be a facilitating factor for policy work (see Group dynamics in Fig. 1).

On the other hand, District A had only high school teachers on the Energy Task Force because they had difficulty recruiting middle and elementary school teachers. The Energy Task Force in District A experienced repercussions of lack of representative involvement when they presented the SEP\&EP to district staff for the first time in the fall of 2009. Many teachers who were not involved in the process felt uncomfortable with some of the policies and felt like they did not have enough opportunity to provide input to the plan. One participant further explained by saying: “...it's difficult to change people and if they're already 
comfortable [with their current] teaching, it's always more work to implement new ideas." There was a similar situation in District C where there were no middle school representatives. One teacher from District C mentioned, “... it was hard to get people involved. There's no one from middle school... that in and of itself was a major obstacle." As shown in Fig. 1, these comments revealed that the facilitative potential of Group dynamics can be affected by Group representation. District B had a variety of grade levels and subjects represented on their Energy Task Force and reported that both of these supported their efforts to complete their SEP\&EP.

\subsubsection{Environmental literacy components}

For each Energy Task Force, environmental literacy was a key facilitator. Attributes within the Cognitive domain, Affective domain, and Behavioral domain played facilitative roles, helping to overcome many of the barriers. Efficacy beliefs were found to be an especially important factor in supporting plan development and completion.

6.2.1.1. Cognitive domain. As diagramed in Fig. 1, the Cognitive domain included the operational knowledge of the school energy system, understanding of energy conservation, and experience and interest in energy education. Participants with higher levels of each of these factors facilitated the development of the school energy policy and education plan.

SEP\&EP development was facilitated in districts that had Energy Task Force members in the field of energy (e.g., facility managers) or energy knowledgeable participants (e.g., teachers who had taken an energy education course). For example, in District A, all three of the primary Energy Task Force members had taken at least one KEEP course; therefore, they had a general understanding of energy education. One teacher from District C commented: "I think that it helped having people that worked on energy lessons and had an idea of what they did and they could share that with others..." The Energy Task Forces valued advice from experts in the field of energy education and resource management. One District $C$ participant reported, “... there was an extra pair of eyes [energy consultant] that had expertise who could give a little bit of guidance when we were going into the ditch..."

6.2.1.2. Affective domain. The Affective domain included valuing environmental protection in general and having a specific interest in energy conservation, regardless of the cognitive skills participants had with regard to energy systems. Teachers of the Energy Task Forces were interested in educating their students, co-workers, and community members about energy. They wanted to establish a plan to raise teacher and staff awareness of the energy policy and energy in general; teachers would then feel more comfortable teaching energy concepts in their classes. The importance of an administration valuing energy efficiency and supporting the team is indicated in Fig. 1 by heavier lines.

As mentioned previously, time availability and scheduling conflicts were significant barriers among all three school districts (indicated by dotted lines in Fig. 1). Energy Task Force members' passion and dedication to energy efficiency were instrumental in persisting through the process despite such challenges. Notably, they all went into the process with the desire to work in a building that had policies in place to make sure the space was both comfortable and energy efficient. By having a school energy policy with clear guidelines to follow, they felt they were more likely to realize the energy efficiency and energy literacy they desired. Following are quotes from members of each district Energy Task Force expressing the importance of having energy policies and education plans in place for their schools.
District A: “... [students] also get the benefit of getting those lesson plans and having hands-on experiences with some of those activities and know that it's just not for science teachers to do it, it's not. You just don't learn it one day... it's a life lasting curriculum that they're going to keep growing with."

District B: "What the district is trying to do with their energy policy I think is not common knowledge and I think through this, the teachers and students will become more aware of simple things that can be done and how important those simple things will be in making a difference in our energy use."

District C: "I think that our energy education plan is there to get students educated and they can go out and make a difference with asking faculty to do different things in energy conservation. And then, because the students are out there, the teachers are aware of energy and therefore, they might be more apt to do what's being asked for in the energy [policy]."

6.2.1.3. Behavioral domain. Many Energy Task Force members either practiced or wanted to adopt environmentally responsible behaviors to help save energy for a variety of reasons. A main reason was that saving energy at school helped save the school money; this understanding motivated and supported involvement. They also understood that using less energy would reduce the impact the school has on the environment. As one member from District A shared, "I think [the SEP\&EP] is a great project that makes everyone aware of what effects we have on the building... simple habits can cost a ton of money. The younger we can ingrain this into our children, the better our world will be." They also understood that, in most cases, a decrease in energy consumption results in smaller utility bills. The money "saved" by being more energy efficient could be spent on resources, salaries, or future energy projects. Furthermore, many energy conservation and management strategies that are applied in a school setting can be transferred to the home. If an action or change in behavior will save energy in school, there is a good chance it will save energy at home as well.

In District C, the variety of people on the Energy Task Force brought a lot of different experiences to this group. There were several teachers that had first-hand experience teaching energy education in their classrooms, and an Energy Manager with over 6 years of experience working in the district to reduce energy consumption. The influential membership of the Energy Task Force is exemplified by the following statement, "I have taught for 25 years. I kind of have a historical perspective to bring to it and [have] seen lots of different programs that have been brought into the classrooms over the years."

6.2.1.4. Efficacy beliefs. Perhaps one of the most interesting findings is the confidence members had that the SEP\&EP, and their involvement, would make a difference. According to a District $C$ Energy Task Force member: "[The SEP\&EP] gives a school community a great opportunity to rally behind something that has significant educational, environmental and economic benefits. It also provides an opportunity for educators to work collaboratively with operations/ facilities staff in facilitating a major cultural change in the school community." Efficacy beliefs, or the conviction that one's actions will be met with the intended response, were impacted by the Institutional and Management Framework, as strong institutional and management factors increased the locus of control and personal responsibility perceived by the participants. Many participants thought that it was important to increase the responsibility of the building occupants to use energy wisely. "Everyone within the school and district should be responsible for energy conservation," noted a District A representative. They felt that this increase in responsibility would help the district reach its energy conservation goals. One teacher from District B noted, "I think [the planning process] 
contributed to those of us who were more a part of the group right now and making us more aware of it and what we're going to be able to take back to our schools and make them aware of it. It probably didn't have as much of an impact on the other occupants at the [other] schools yet."

There were some individuals who believed their efforts may not matter and that implementation and follow through on the SEP\&EP would not be forthcoming, while others - especially those in a position of power - were confident that their efforts were worthwhile. Essentially, if participants felt that the administration was committed to implementing the policy and the plan and that their involvement was valued (even if not financially compensated), then they were more likely to participate effectively in the SEP\&EP development process. Without this support, they tended to feel they lacked the time and availability to participate.

\section{Discussion and recommendations}

This study shares how different school cases followed outlined steps for developing complementary energy policy and energy education plans. To gain further insights into the process, additional case studies should be conducted in different locations. While some of the specific workshops and trainings mentioned in the steps will not be available in other locations, the general process for a team working on a school energy policy and education plan should include professional development support for teachers, administrators, and facility managers. Likewise, procuring the results of the school's energy audit is critical to the process and, ideally, the team should participate in the audit. Although there were variations in perceptions of the ease of the steps and the order in which the steps were taken, the Energy Task Force members generally agreed that the outlined steps were useful and supportive for their policy and plan development.

This study also provides a further understanding of the attributes of actors involved with the successful development of policies and education plans. The focus of the analysis for this case study was the team members (the Energy Task Force) involved in school energy policy and education plan (SEP\&EP) development; therefore, the findings and recommendations stem from the perceptions of the participants about the process. The results of this exploratory investigation support findings and recommendations of other studies that advocate for improving community discourse and building teacher agency in developing education policies and plans (e.g., Braun et al., 2010; Stevenson, 2006).

Related to community discourse, analysis of the teams' responses revealed the importance of a supportive administrative framework to help ensure success of the process. This study was limited to the perceptions of members of small teams working on the plans and policies. While the teams included teachers and administrators, stronger participation of and perspectives provided by community members and students would benefit the process. Regarding teacher agency, analysis of the cases in this project revealed that leadership and attributes of environmental literacy played key roles in empowering actors to complete the SEP\&EP development process. In particular, the domains of the literacy framework developed by Peri (1996) were evident in the participants that most effectively completed their plans. Other researchers in the field of environmental education and conservation have frameworks or studies that have similar attributes to the Peri model. Her framework was based on a review of earlier studies (Hungerford et al., 1980; Hungerford and Volk, 1990; Iozzi and Marcinkowski, 1990; Roth, 1990). More current studies emphasize the importance of self-efficacy for responsible environmental behaviors (DeWaters and Powers, 2011; Monroe, 2003; Tanner and Kast, 2003).
The Energy Task Forces in this study encountered barriers and challenges, but efficacy beliefs and their passion for energy conservation - complemented by leadership and administrative support - were instrumental in helping members overcome these barriers and successfully draft the SEP\&EPs. Additional empirical research is needed to examine the proposed framework of facilitating and obstructing factors. In particular, additional studies can assess the environmental literacy of school energy policy actors, especially their self-efficacy, to verify the extent to which the various domains empower Energy Task Force members. For example, the Thøgersen and Grønhøj (2010) study applied a conceptual framework based on Bandura's (1986) social cognitive theory to analyze energy saving behaviors in Danish households. Various aspects of social behavior theory (Bandura, 1978; Ajzen, 2002) should be applied to learning more about the motivating factors of self-efficacy in school energy policy work. While environmental attitudes and behaviors have been extensively researched (Aoyagi-Usui et al., 2003; Barr, 2007; Corraliza and Berenguer 2000; Dunlap, et al., 2000; Hines et al., 1987), these attributes present additional opportunities for research into how they relate to school energy policy development.

If the role of environmental (and energy) literacy is confirmed, the importance of developing these attributes in policy actors and educators in general will be supported. Truly, the domains of environmental literacy - cognitive, affective, behavioral, and efficacy beliefs - can be applied to nearly any field of education; the revelation of these domains in this study emphasizes the importance of building comprehensive teacher agency in energy policy work and energy educational planning, and implementing these plans with fidelity.

The results of this study will be further confirmed by evidence that the SEP\&EPs are executed and maintained. A longitudinal study to examine the outcomes of the policies and plans would provide further insights into the effectiveness of the process. The researchers have learned through informal communications that Energy Task Force members have taken initiatives to implement their plans and policies. For example, 2 years after the plan was developed, members from School District A reported that their policies are still in place and are being followed for the most part. One member shared that the school continues to save energy using the automatic lights in their common areas and hallways, although he has noted that some reinforcement of behaviors is needed regarding other energy use practices. School District B noted that they were able to pilot their energy education plan with one of the elementary schools. They applied for and received a $\$ 3000$ grant to purchase energy education kits from NEED. The district's new Buildings and Grounds Manager was supportive of the energy education pilot and shared information with teachers and their classes regarding new energy saving practices taking place in the district. Teachers from School District $C$ continue to educate students about their solar panels that were purchased and installed according to their SEP\&EP. Their efforts have received some media attention. Other anecdotal reports have been shared with the researchers; however, a more formal longitudinal analysis is recommended for a future study. The increase in number of school energy policies that provide guidelines for school facilities to operate and maintain buildings more efficiently will certainly help the energy conservation movement. It should also be noted that, like many states in the U.S.A., Wisconsin has professional development programs for school building energy efficiency for both teachers and facility managers. The Wisconsin K-12 Energy Education Program (KEEP) was created in 1995 and has built partnerships with organizations and programs that promote energy efficiency in communities. The creation of a school energy policy and education plan grant program was one initiative that was made possible by these partnerships. The stakeholders involved in the initiative hope the outlined steps will serve as a 
guide for other school districts to identify environmentally literate Energy Task Force members to develop school energy policy and education plans, and that this study provides insights on how to facilitate the teams' efforts.

\section{Appendix. Recommended steps for developing a school energy policy and energy education plan}

Note: The steps outlined below were in the original grant; however, they have been revised to make them more relevant to a wider audience outside of Wisconsin. To see the original outline, please contact the corresponding author.

\section{Form an Energy Task Force and meet regularly}

Form an Energy Task Force consisting of teachers, administrators, facility personnel, and ideally community members experienced in energy resource management. This group should have regular meetings to make sure that the following steps are conducted. Subgroups within the Energy Task Force should be formed and assigned specific tasks, such as developing the education plan.

\section{Participate in an energy audit}

The Energy Task Force will participate in an energy audit of the school conducted by an Energy Advisor (a consultant trained in conducting audits in schools).

Note: At the time of the grant, a statewide energy efficiency program (Focus on Energy) was offering free energy audit services to schools. The Task Force was able work with the KEEP outreach specialist and the Energy Advisor to arrange a time when the majority of the Task Force members were available.

\section{Draft a school energy policy and education plan}

The Energy Task Force will meet numerous times to draft and revise the school energy policy and education plan.

Note: For the grant, the Energy Task Force was referred to a school energy policy and education plan Template for guidance when developing the document

(see www.uwsp.edu/cnr/wcee/keep/SchoolEnergyEducation/ \#Template).

\section{Solicit administrative, faculty, and staff suggestions and feedback}

The Energy Task Force will use strategies such as teacher in-services or school-wide surveys to collect information and suggestions from staff (e.g., effectiveness of current energy policies, suggestions from various sectors of the school community regarding the plan, and teacher input regarding energy education).

5. Disseminate information to the community related to the progress of the development of the project

The Energy Task Force will disseminate information to the community related to the progress of the development of the school energy policy and education plan (e.g., school newsletter, Web site, and local newspaper).

6. Teachers on the Energy Task Force (as well as other Teachers from the schools) should participate in an energy education professional development program

Note: For the grant, teachers in Wisconsin were directed to take a KEEP School Building Energy Efficiency Education course (www.
uwsp.edu/cnr/wcee/keep/ProfessionalDevelopment/index. htm\#734) and to work with KEEP to coordinate with the Energy Task Force team to arrange the dates, location, and guest speakers for the course.

7. Administrators and facility managers on the Energy Task Force should participate in school building energy efficiency trainings and workshops

Note: During the grant, two programs were available for school facility managers and administrators to learn about school building energy operations and efficiency. These programs included a Practical Energy Management (PEM) - Schools training (suitable for the administrator and facility manager) and a Building Operator Certification (BOC) program (required for the facility manager).

\section{The Energy Task Force members should review and finalize the school energy policy and education plan and present it to the administering body}

The Energy Task Force will be responsible for making sure that the plan is ready for approval.

\section{References}

Alliance to Save Energy, 2009. About Green Schools. Available from: 〈http://ase.org/ section/program $\rangle$ (accessed 24.08.09).

Allington, R., 1999. Critical issues: crafting state educational policy: the slippery role of research and researchers. J. Literacy Res. 31 (4), 457-482.

Ajzen, I., 2002. Perceived behavioral control, self-efficacy, locus of control, and the theory of planned behavior. J. Appl. Soc. Psychol. 32 (4), 665-683.

Aoyagi-Usui, M., Vinken, H., Kuribayashi, A., 2003. Pro-environmental attitudes and behaviors: An international comparison. Hum. Ecol. Rev. 10 (1), 23-31.

Bandura, A., 1978. Self-efficacy: toward a unifying theory of behavioral change. Adv. Behav. Res. Ther. 1 (4), 139-161.

Bandura, A., 1986. Social Foundations of Thought and Action: A Social Cognitive Theory. Prentice-Hall, Englewood Cliffs, NJ.

Ball, S., Maguire, M., Braun, A., Hoskins, K., 2011. Policy actors: doing policy work in schools. Discourse: Stud. Cultural Politics Educ. 32 (4), 625-639.

Barr, S., 2007. Factors influencing environmental attitudes and behaviors: a UK case study of household waste management. Environ. Behav. 39 (4), 435-473.

Bontrager, R., Hubbard, C., 1977. A model for education: energy-water consumption decision making. U.S. Department of Health, Education \& Welfare National Institution of Education. Washington, DC.

Braun, A., Maguire, M., Ball, S., 2010. Policy enactments in the UK secondary school: examining policy, practice and school positioning. J. Educ. Policy 25 (4) 547-560.

Cavallo, A., Gerber, B. Marek, E., Chiodo, J, 1998. Research on teachers' attitudes and understandings of interrelationships among energy, environment, and public policy. Education 119, 67-78.

Champeau, R., 1997. Are We Walking the Talk? Environmental Education in Wisconsin. Wisconsin Center for Environmental Education, Stevens Point, WI.

Chrispeels, J.H., 1997. Educational policy implementation in a shifting political climate: the California experience. Am. Educ. Res. J. 34, 453-481.

Corraliza, J.A., Berenguer, J., 2000. Environmental values, beliefs and actions: situational approach. Environ. Behav. 32, 832-848.

DeWaters, J.E., Powers, S.E., 2011. Energy literacy of secondary students in New York State (USA): a measure of knowledge, affect, and behavior. Energy Policy 39 (3), 1699-1710.

Dunlap, R.E., Van Liere, K.D., Mertig, A.G., Jones, R.E., 2000. New trends in measuring environmental attitudes: measuring endorsement of the new ecological paradigm: a revised NEP scale. J. Soc. Issues 56 (3), 425-442.

Gittell, M., 1995. Participants and Participation: A Study of School Policy in New York City. Center for Urban Education, New York City.

Hines, J.M., Hungerford, H., Tomera, A., 1987. Analysis and synthesis of research on responsible environmental behavior: A meta-analysis. J. Environ. Educ. 18, 1-8.

Hungerford, H., Peyton, B., Wilke, R., 1980. Goals for curriculum development in environmental education. J. Environ. Educ. 11 (3), 42-47.

Hungerford, H., Volk, T., 1990. Changing learning behavior through environmental education. J. Environ. Educ. 21 (3), 9-21.

Iozzi, L., Marcinkowski, T., 1990. Assessment of learning outcomes in environmenta education. In: Maldague, M. (Ed.), Methods and Techniques for Evaluating Environmental Education. UNESCO, Paris.

Merriam, S.B., 1998. Case Study Research in Education. Jossey-Bass Publishers, San Francisco.

Monroe, M., 2003. Two avenues for encouraging conservation behaviors. Hum. Ecol. Rev. 10 (2), 113-125. 
NEED, 2012. National Energy Education Development Project. Retrieved June, 2012, Available from: 〈http://www.need.org/〉.

Orth, K., 2009. Lighting the way. School Planning and Management. Available from: 〈http://www.peterli.com/spm/archive.php?article_id=2117〉 (accessed 25.06.12).

Panaro, S., Rickert, M., 2011. 2010 Green Schools Survey. Available from Wisconsin Green Building Alliance: 〈http://wgba.shuttlepod.org/Resources/Documents/〉 (accessed 22.04.11).

Peri, P., 1996. The development of an instrument to assess environmental literacy of eleventh grade students in Wisconsin. Master's thesis. University of Wisconsin, Stevens Point.

Princeton Energy Resources International, Powell Energy Associates, Alliance to Save Energy, 2004. School Operations and Maintenance: Best Practices for Controlling Energy Costs. A Guidebook for K-12 School System Business Officers and Facilities Managers. US Department of Energy, Washington, DC.

Rickert, M., 2011. School energy policy and education plans: a case study of plan development in three Wisconsin school communities. Master's thesis. University of Wisconsin, Stevens Point.

Roth, C.E., 1990. Environmental literacy: its roots, evolution and direction in the 1990s. Clearinghouse for Science Mathematics and Environmental Education. Columbus, OH (ERIC Document Reproduction Service no. ED348235).

Stanley, W., 1957. The search for consensus. Educ. Leadersh. 14 (7), 404-408.
Stevenson, R., 2006. Tensions and transitions in policy discourse: recontextualizing a decontextualized EE/ESD debate. Environ. Educ. Res. 7 (3-4), 277-290.

Stevenson, R., 2007. School and environmental/sustainability education: from discourses of policy and practice to discourses of professional learning. Environ. Educ. Res. 13 (2), 265-285.

Superfine, A., Kelso, C., Beal, S., 2010. Examining the process of developing a research-based mathematics curriculum and its policy implication. Educ. Policy 24 (6), 908-934.

Tanner, C., Kast, S.W., 2003. Promoting sustainable consumption: determinants of green purchases by Swiss consumers. Psychol. Mark. 20 (10), 883-902.

Thøgersen, J., Grønhøj, A., 2010. Electricity saving in households-a social cognitive approach. Energy Policy 38 (12), 7732-7743.

U.S. Department of Energy, 2009. EnergySmart Schools National Financing Roundtable-Key Outcomes. 〈http://apps1.eere.energy.gov/buildings/publica tions/pdfs/energysmartschools/ess_roundtable_rpt-II.pdf $>$ Washington, DC.

U.S. Environmental Protection Agency, 2005. Teaming Up to save energy: protect our environment through energy efficiency. US EPA. Washington, DC (Document no. 430-K-05-007).

Witcher, A., 2001. Promoting teachers as participants in policy design. Kappa Delta Pi Rec. 37 (2), 88-90.

Yin, R., 2009. Case Study Research: Design and Methods (Applied Social Research Methods). Sage Publications, Inc., Thousand Oaks, CA. 